\title{
An open letter to all of the medical journals who send me daily offers to publish my "high-impact research in next month's issue"
}

Cite as: CMAJ 2018 October 1;190:E1172. doi: 10.1503/cmaj.180593

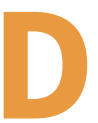

ear journal editor:

Thank you for your unsolicited email contact introducing me to your journal that I have never heard of. I congratulate you for choosing a journal title that sounds like an established publication with a high impact factor. Indeed, use of the words "annals" or "archives" certainly helps to give the impression that your journal has existed for longer than three months. If you are open to suggestions, perhaps you might consider renaming the journal the International Annals and Archives and Proceedings of Endocrinology. That sounds really important. According to your email, your journal accepts a wide range of manuscript types including research, reviews, short communications, short stories and poetry pertaining to major advances in endocrinology, genetically modified foods, hair colourants and beekeeping.

I am quite flattered that you decided to contact me as a potential author after reading that article I published 15 years ago. It has only been cited twice, but I am pleased to know that, finally, someone has recognized the genius of that work and contacted me to enquire about my next big contribution.

It is quite fortuitous to have received this email today; I have been thinking that I would like to have another publication for my curriculum vitae next month to impress my department head, and I admit that I sometimes find the peer review process to be annoying, especially when those expert reviewers somehow fail to see the brilliance of my research.

I am pretty impressed that you are able to promise publication next month before even having received my manuscript. Of course, you also mention the small matter of payment - I guess that $\$ 3000$ seems to be the going rate to ensure that my name gets

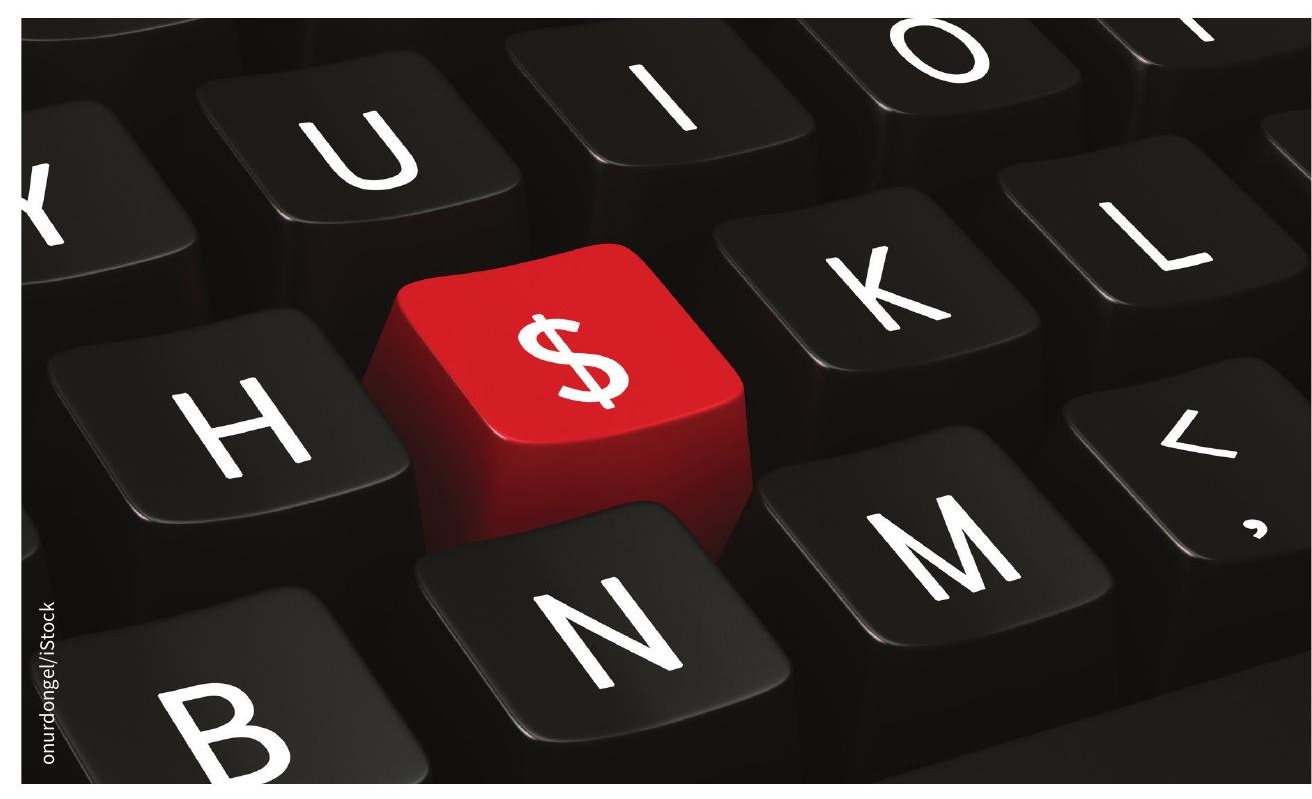

attached to a publication. And here I have been hanging on to the romantic idea that scientists needed to prove that their work was accurate and deserving of being accepted by others. I must say, your way is so much easier!

By the way, if you happen to sit beside that person who sends me weekly offers of editorial positions at journals that are completely unrelated to anything I have ever published in my career, maybe you could let them know that I am too busy right now. But if there are no requirements for actual expertise, I know a guy with a degree in film studies who is looking for something to do - he might be ideal for Recent Advances in Interventional Hematologic Neonatology.

One last minor request - please accept my regrets for all those invitations your offshore medical media company has sent me, inviting me to vaguely named conferences like IAEU-2018, which sounds like a big meeting even though the acronym expands to Interesting Advances in the Endocrine Universe 2018. I admit I was initially flattered at being an invited speaker, especially because the invitation seemed to be completely open-ended for a topic of my choice (should the talk be medical or are you open to a little stand-up routine I have been polishing over the years? My kids think it is hilarious!). Anyhow, I note that the invitation comes with an offer of $10 \%$ off the registration fees ... so I guess there will be no limo to pick me up at the airport, eh?

Thanks for your never-ending interest in my apparent expertise.

\section{Gregory Kline MD}

Cumming School of Medicine, University of Calgary, Calgary, Alta.

This article has been peer reviewed. 